\title{
CERAMIKA Z ORNAMENTEM PASMOWO-GRZEBYKOWYM Z OSADY KULTURY PUCHARÓW LEJKOWATYCH W POGANICACH, POW. SLUPSKI, STAN. 4. PRZYCZYNEK DO STUDIÓW NAD KIERUNKAMI KONTAKTÓW INTERREGIONALNYCH LUDNOŚCI GRUPY LUPAWSKIEJ
}

\author{
POTTERY WITH A BAND AND COMB ORNAMENT FROM \\ THE FUNNEL BEAKER SETTLEMENT IN POGANICE, \\ SŁUPSK COUNTY, SITE 4. \\ CONTRIBUTION TO THE STUDY OF DIRECTIONS \\ OF INTERREGIONAL CONTACTS \\ OF THE ŁUPAWA GROUP COMMUNITIES
}

\author{
Jacek Wierzbicki \\ Instytut Prahistorii, Uniwersytet im. Adama Mickiewicza \\ ul. Umultowska 89D, 61-614 Poznań, Poland \\ jacwierz@amu.edu.pl
}

\begin{abstract}
During the excavations within the settlement of the Funnel Beaker culture in Poganice, Słupsk county, carried out in the 1970s, two fragments of vessels decorated with band and comb ornament were discovered. This discovery appears to be one of the north-westernmost appearances of such a type of pottery, very common in Chełmno land, and considered to be one of the indicators of the Mątwy group of the Funnel Beaker culture. Their presence at the site of the Lupawa group of the Funnel Beaker culture permits to follow the ways the pottery got into the Łupawa River basin. It might have been via the route along the left side edge of the lower Vistula valley, and further on along the courses of the Wierzyca and Słupia Rivers into Central Pomerania.
\end{abstract}

KEY WORDS: Neolithic, Funnel Beaker culture, Narva culture, band and comb ornamentation.

Problematyka powiązań interregionalnych ludności grupy łupawskiej kultury pucharów lejkowatych (KPL) była podnoszona w zasadzie od samego początku badań nad tą jednostką, najczęściej w związku z jej genezą (topogenezą), przy czym co zrozumiałe - koncentrowano się na rejonie Meklemburgii albo szerzej: północ- 
nych i środkowych Niemiec, wschodniej Jutlandii, a nawet południowej Szwecji (Jankowska 1980, s. 157-159; 1990, s. 254-255). Jednak według D. Jankowskiej równie istotne były kontakty z szeroko rozumianym południem, ponieważ:

Materiał masowy zaś jest efektem skrzyżowania i przetworzenia cech północnej (zapewne meklemburskiej) i wschodniej (wielkopolskiej) grupy KPL. Skrzyżowanie to dokonało się najprawdopodobniej wcześniej, przed przybyciem do rejonu Łupawy. [...] Prawdopodobnie za rejon kontaktów i tworzenia zalążków grupy trzeba uznać ziemie Pomorza Środkowego w dorzeczu Parsęty. [...] Bezpośrednią przesłanką przemawiającą za tą koncepcją są materiały ze stanowiska w Kisielicach, b. pow. Białogard, charakteryzujące się niejednorodnym zestawem cech diagnostycznych z przewagą elementów późnowióreckich. Zgodnie z naszą hipotezą w rejonie środkowej Parsęty ludność późnej fazy wióreckiej wchodziła w związki z nielicznymi zapewne grupami reprezentującymi kontynentalny wariant grupy północnej KPL, które przyniosły ze sobą równocześnie niektóre cechy kultury baalberskiej i michelsberskiej. Obszar ten byłby swego rodzaju punktem etapowym w wędrówce ludności neolitycznej na wschód (Jankowska 1980, s. 157-158).

D. Jankowska zakładała zatem, że identyfikowane w materiale ceramicznym grupy łupawskiej elementy późnowióreckie, genetycznie związane z terenami Wielkopolski, przeniknęły w rejon dorzecza Łupawy z zachodu, znad Parsęty. Na takiej wizji interregionalnych więzi ludności łupawskiej zaważyło przede wszystkim silne przekonanie o generalnie późnej pozycji chronologicznej całej grupy łupawskiej. Nie mogło być inaczej, skoro - jak sugerowała wspomniana autorka - łupawska stylistyka ceramiki miała kształtować się w dorzeczu Parsęty na bazie takich materiałów, jak z wiórecko-lubońskiego stanowiska 1 w Kisielicach (Siuchniński 1969, s. 56, tabl. V; 1972, s. 71) (obecnie Białogard-Kisielice). W późniejszym i szerszym ujęciu najwcześniejsza fala napływu elementów kulturowych z rejonu Wielkopolski, datowana na fazy IIIB/IIIC lub początek fazy IIIC kujawskiej KPL, czytelna była według D. Jankowskiej „tylko w północnej części Pomorza Zachodniego w strefie pobrzeża Zalewu Szczecińskiego, co może sugerować, iż w pierwszym okresie kolonizacja pucharowa odbywała się szlakiem warciańsko-odrzańskim" (Jankowska 1990, s. 246-247). Wtedy też „pierwotna hipoteza o »zachodniej« genezie komponentu wióreckiego w grupie lupawskiej” została zweryfikowana. D. Jankowska zasugerowała, że istniała „całkiem realna możliwość dotarcia do rejonu międzyrzecza Wieprzy-Słupi niewielkich grup o rodowodzie kujawskim z Krajny lub Pomorza Gdańskiego za pośrednictwem omówionych wyżej wodnych szlaków komunikacyjnych [tj. wzdłuż Wierzycy - J. W.], co mogło nastąpić już przynajmniej w fazie IIIB" (Jankowska 1990, s. 253). Potwierdzeniem tej hipotezy miałaby być położona nad górną Wieprzą osada w Czarnicy, pow. bytowski, stan. 1 (Jankowska 1990, s. 253-254), co zostało jednak zakwestionowane ze względu na obecność na tym stanowisku typowych dla grupy łupawskiej wątków zdobniczych (Wierzbicki 1999, s. 247, przyp. 199). 
Pierwszą przesłanką świadczącą o istnieniu oddziaływań ogólnie południowych, ale które w rejon dorzecza Łupawy mogły docierać wzdłuż dolnej Wisły, było odkrycie w grobowcu $3 \mathrm{z}$ cmentarzyska megalitycznego na stan. $18 \mathrm{w}$ Lupawie fragmentu naczynia z motywem zdobniczym będącym zapewne symbolicznym wyobrażeniem wozu czterokołowego (Weber 1983, 52, tab. VII: 9; Wierzbicki 1997, ryc. 8:D), znanego m.in. z osady w Inowrocławiu-Mątwach, stan. 5 (Kośko 1981, s. $152-153$, ryc. $31: 3$, tab. VIII). Następną było znalezienie na cmentarzysku megalitycznym w Łupawie, stan. 27 (Wierzbicki 1997, s. 11, 13-14, ryc. 7:3), fragmentu naczynia zdobionego wątkiem typowym dla tzw. stylistyki wiórecko-jezuickiej (Prinke 1988), znanej też jako typ Toruń-Mokre (Kukawka 1997, s. 73-74; 2010b, s. 112; 2012, s. 222-223), której chronologię określa się na Kujawach na fazę IIIA KPL (Kukawka 2010b, s. 154, ryc. 10; 2012, s. 222; Prinke 1988, s. 100), a na ziemi chełmińskiej na 3900-3600 BC (Kukawka 2010b, ryc. 10). Echa tej stylistyki można także zauważyć w ceramice z kilku stref osady w Poganicach, pow. słupski, stan. 4 (Świderski, Wierzbicki 1990, tab. XIV: 1768, XVIII: 1982). Nie wnikając głębiej w dość kontrowersyjne rozważania na temat genezy tego zjawiska (Czerniak, Kośko 1993, s. 115-118; Kośko 1988, s. 153; Kukawka 1997, s. 74-75; 2010b, s. 112; Prinke 1988, s. 103-104), można przypuszczać, że również idea tej ornamentyki dotrzeć musiała na tereny zajmowane przez grupę łupawską drogą prowadzącą wzdłuż Wisły na północ, jak jednoznacznie sugeruje to dyspersja tego typu zdobnictwa (Kukawka 2010b, ryc. 14; Wierzbicki 1997, ryc. 8:A). Nie są to jednak jedyne argumenty na rzecz istnienia szlaku wiślanego.

Osada KPL w Poganicach, stan. 4 (obecnie w granicach wsi Łupawa), była badana wykopaliskowo w latach 1970-1991 (z przerwami) przez ówczesną Katedrę Archeologii, a następnie Instytut Prahistorii Uniwersytetu im. Adama Mickiewicza w Poznaniu. Jednym $z$ efektów prac archeologicznych na tym stanowisku oraz na sąsiednich cmentarzyskach megalitycznych było zdefiniowanie w 1977 r. grupy łupawskiej KPL (Jankowska 1977). Na terenie osady w Poganicach wyróżniono dziewięć obszarów najintensywniej użytkowanych osadniczo, charakteryzujących się obecnością wyraźnej warstwy kulturowej oraz pozostałościami zabudowy słupowej, tzw. stref, które były interpretowane jako odrębne osiedla, częściowo sobie współczesne (Jankowska 1980, s. 83; Szurkowska 1982, s. 5; Wierzbicki 1999, s. 18, przyp. 19), oraz jedną strefę o charakterze gospodarczym (Jankowska, Wierzbicki 1993). Strefa 7 jest najbardziej wysuniętą na zachód częścią osady poganickiej, położoną przy krawędzi terasy opadającej stosunkowo stromą skarpą do rzeki Łupawy (Jankowska 1980, ryc. 4; Wierzbicki 1999, ryc. 56). W latach 1973-1980 przebadano tam obszar o wymiarach $20 \times 17,5 \mathrm{~m}$ oraz założono trzy wykopy sondażowe o wymiarach $5 \times 2,5 \mathrm{~m}$, odkrywając $\mathrm{w}$ sumie powierzchnię $387,5 \mathrm{~m}^{2}$. Pozyskano stamtąd zbiór ceramiki liczący ok. 76 tysięcy fragmentów (Szurkowska 1982, s. 5, 8; Wierzbicki 1999, s. 63; 2013, s. 437-438), z których wiele ornamentowanych jest motywami nieznajdującymi analogii w innych materiałach grupy łupawskiej. 
Wśród nich znalazły się dwa ułamki, które nie były dotąd publikowane ${ }^{1}$, choć występujące na nich wątki zdobnicze zostały sklasyfikowane w wykazie typów wątków zarejestrowanych $\mathrm{w}$ materiałach ceramicznych ze stanowisk łupawskiego mikroregionu osadniczego KPL jako typy Z-460a i Z-465a (Wierzbicki 1999, s. 100-101). Na obu wystąpiła tzw. pasmowa ornamentyka grzebykowa (Jażdżewski, 1936, s. 247). Pierwszym z nich jest fragment górnej części naczynia (ryc. 1:1) zdobiony na krawędzi ukośnymi nacięciami, a w strefie podkrawędnej zewnętrznej poziomym falistym pasmem linii rytych wykonanych trójzębnym grzebykiem. Poniżej znajdują się wykonane w podobny sposób wielozębnym grzebykiem pasma ukośne (pz: xG-83 [198] |+G-91 [183]²). Drugi fragment (ryc. 1:2), pochodzący z nieokreślonej części naczynia, pokryty jest nachodzącymi na siebie różnokierunkowymi pasmami linii rytych wykonanych z użyciem podobnego narzędzia (?: +G-93 [183, $183,198])$. Ten typ zdobnictwa ewidentnie związany jest z tzw. mątewskim elementem kulturowym (mkk) (Kośko 1981, s. 73), choć oba ułamki pod względem technologicznym odpowiadają typowej ceramice grupy łupawskiej KPL (Wierzbicki 1999, s. 248). Nie jest to jednak fakt wyjątkowy (Kukawka 2010b, s. 123). Zdobnictwo takie było stosowane, jak się wydaje, wyłącznie w kontekście materiałów KPL, a jego cechy technologiczne i morfologiczne, ornamentyka i zasięg przestrzenny, a także historia badań, były już kilkakrotnie omawiane i podsumowywane ${ }^{3}$, dlatego nie będą tutaj powtarzane. Jego wschodnioeuropejskie pochodzenie nie budzi wątpliwości, chociaż nie do końca wyjaśnione kwestie jego chronologii i genezy wciąż rodzą spory (Daszkiewicz, Prinke 2001, s. 121; Kośko 2010, s. 14).
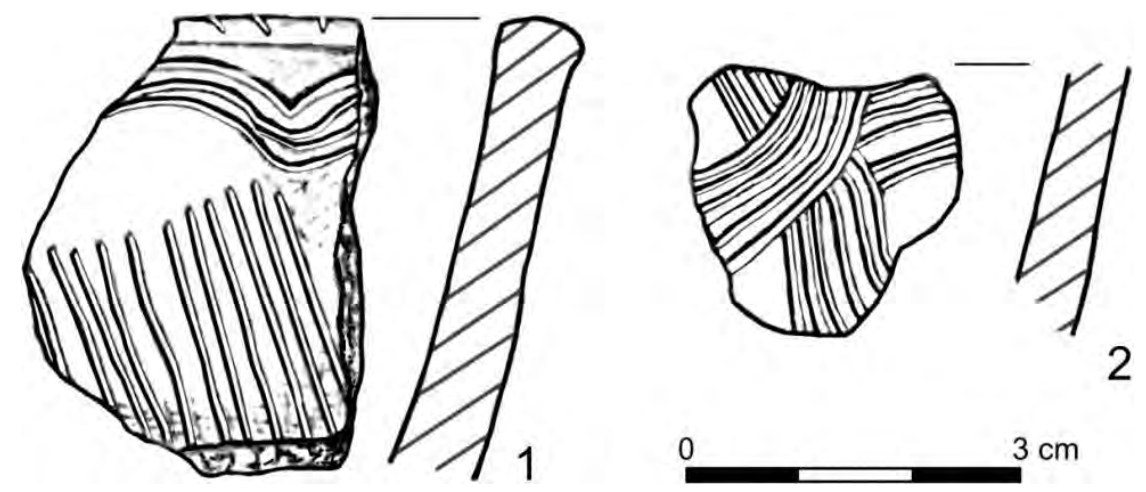

Ryc. 1. Poganice, pow. słupski, stan. 4. Fragmenty ceramiki z ornamentem pasmowo-grzebykowym

Fig. 1. Poganice, Słupsk county, site 4. Fragments of pottery with band and comb ornament

\footnotetext{
${ }^{1}$ Jedynie ich rysunki zaprezentowane zostały w pracy magisterskiej K. Szurkowskiej (Szurkowska 1982, tabl. XIII-XIV).

${ }^{2}$ Zapisy wątków zdobniczych według metody A. Kośki (1981, s. 34-42, tab. 1).

${ }^{3}$ Ostatnio np. Daszkiewicz i Prinke 2001, s. 121-122, ryc. 6; Kukawka 2010b, s. 147, 153-154.
} 
Te dwa ułamki ceramiki z ornamentem pasmowo-grzebykowym nie są jednak pierwszymi tego rodzaju znaleziskami, o których wspomniano w kontekście materiałów grupy łupawskiej. Już w 2001 r. D. Jankowska omawiając obecność elementów „leśnych” w tej jednostce kulturowej, podkreśliła, że „Zarejestrowano też pojedynczy ułamek naczynia $\mathrm{z}$ »mątewskim« motywem pasmowo-grzebykowym, który za S. Kukawką (1991) uznaję za ewidentny północno-wschodni komponent »leśny« (ryc. 3 i 4)" (Jankowska 2001, s. 90). Autorka nie sprecyzowała niestety bliżej wyglądu wzmiankowanego fragmentu ceramiki, tylko odesłała czytelnika do dwóch rycin, na których przedstawiono łącznie 45 ułamków naczyń. Ze względu na rodzaj zdobnictwa można brać pod uwagę jednak tylko jeden z nich (Jankowska 2001, ryc. 3:18), lecz w rzeczywistości nie jest on ornamentowany wątkiem „mątewskim”, gdyż jest to znajdujący się na wewnętrznej powierzchni naczynia zwielokrotniony zygzak wykonany w technice rycia (pw: ... x B-18: 7), będący zapewne częścią typowego podkrawędnego wątku lubońskiego. Fragment ten był już publikowany wcześniej (Świderski, Wierzbicki 1990, tab. 22: 1066, tab. IV: 1066) i został tam zinterpretowany, zgodnie z przypuszczeniem A. Kośki (1984, s. 43, 45), za pośrednio związany genetycznie ze strefą nadsoławską i ugrupowaniem walternienburskobernburskim (Świderski, Wierzbicki 1990, s. 130).

Dzisiaj nie istnieje jeden pogląd na problem genezy pasmowego zdobnictwa grzebykowego i jego relacji z KPL (Daszkiewicz, Prinke 2001, s. 124; Kukawka 2010a, s. 22, 28; 2010b, s. 149-153; Werra 2012, s. 229-230, 233). „Obecne istotne różnice w poglądach, niezmienne od kilkunastu lat..." (Kukawka 2001, s. 82) przy wyczerpaniu dostępnych argumentów doprowadziły do paradoksalnej sytuacji, w której dwaj główni dyskutanci, A. Kośko i S. Kukawka, odwołali się w tym samym momencie do opisu omawianej ceramiki sprzed 75 lat autorstwa K. Jażdżewskiego, cytując przy tym jego słowa (Kośko 2010, s. 11; Kukawka 2010a, s. 19-20):

Na obszarze południowej części woj. pomorskiego, północnej części woj. poznańskiego, północno-zachodniej części woj. warszawskiego i na terenie woj. łódzkiego spotyka się oryginalną odmianę naczyń, których kształt nie da się narazie określić, gdyż ułamki zbyt są małe i nieliczne. Można tylko zauważyć, że większość z nich ma proste i pionowe ściany. Same ułamki są prawie zawsze nadzwyczaj porowate, pozatem wykonane z tej samej nieszlamowanej gliny, o miękkim czarnym przekroju, co reszta naczyń kultury puharów lejkowatych. Ornamenty na tych naczyniach wykonane były kilkuzębnymi grzebykami. Są to linje faliste poziome i pionowe oraz pasma proste krzyżujące się pod ostrym kątem. Całość ornamentów jest wykonana ze znacznym niedbalstwem. Z tego wnosić można, że były to naczynia pospolitego przeznaczenia [...]. Do ceramiki tej nie znam narazie analogji z innych terenów (Jażdżewski 1936, s. 247).

Przez 45 lat wypowiedź ta nie budziła większych emocji, a kwestia ornamentyki pasmowo-grzebykowej pozostawała na marginesie innych zagadnień (Kukawka 2010a, s. 20). Dopiero po opublikowaniu pracy A. Kośki, który ten typ ornamentyki 
uczynił jednym z podstawowych wyróżników tzw. grupy mątewskiej, a miałaby ona powstać wskutek przyjęcia „wzorców egzogennych z kręgu kultur strefy stepulasostepu nadczarnomorskiego" (Kośko 1981, s. 5, 72-95; 2003, s. 77, 79-81, fig. 8), pojawiły się głosy polemiczne. Część z nich negowała związki mątewskiego komponentu kulturowego z kulturą trypolską (Jastrzębski 1984, s. 182-183), część wskazywała na inne możliwe źródło inspiracji, uznając za bardziej prawdopodobne łączenie tego typu materiałów z wpływami subneolitycznymi, idącymi nie z południowego wschodu, a z północnego wschodu, z kręgu kultury Narva (Kukawka 1989 , s. 9-15; 1991, s. $149,139,154-155 ; 1997$, s. 152-157; 2001, s. 76-77, 80-81, ryc. 2 ; 2010a, s. 21; 2010b, s. 174), a nawet, jak uważa S. Kukawka, „Pełna zgodność technologii, makro- i mikromorfologii i zdobienia sugeruje, że zasięg ceramiki »mątewskiej« należałoby przesunąć przynajmniej po Estonię [...]. Z moich badań ceramiki subneolitycznej ze strefy przybałtyckiej wynika, że naczynia o cechach mkk występują także w obwodzie leningradzkim" (Kukawka 2010b, s. 174). D. Prinke natomiast zaproponowała nową koncepcję, polegającą na rozdzieleniu naczyń zdobionych w technice pasmowo-grzebykowej od KPL i uznania ich za odrębny byt poświadczający obecność „bliżej jeszcze niezidentyfikowanej kultury ze Wschodu, rozprzestrzeniającej się niezależnie od KPL i całkowicie wobec niej autonomicznej" (Daszkiewicz, Prinke 2001, s. 121, 128-129). Jednak ta „robocza hipoteza”, zgodnie z którą tak ornamentowana ceramika w północnej części Kujaw (Kotlina Toruńsko-Bydgoska) miałaby być starsza od osadnictwa kultury ceramiki wstęgowej rytej, a więc istniałaby od ok. $5400 \mathrm{BC}^{4}$, choć bardzo kreatywna (Kośko 2010, s. 17), nie ma w istocie absolutnie żadnych podstaw źródłowych (Kukawka 2010b, s. 151, przyp. 20).

Według S. Kukawki związki KPL z kręgiem kultury Narva nie ograniczały się jedynie do ziemi chełmińskiej. Są one wyraźnie czytelne również po lewej stronie Wisły, zwłaszcza na Kujawach. Równocześnie z wyodrębnieniem się grupy chełmińskiej (ok. 3700/3600 BC) na Kujawach pojawiają się w ceramice pewne elementy analogiczne do tych, które można zaobserwować po prawej stronie Wisły. Naczynia te są niemal wyłącznie zdobione wątkami pasmowo-grzebykowymi, mającymi swoje pierwowzory w szerokiej strefie subneolitycznej, a ich początki w obrębie KPL na ziemi chełmińskiej sięgają ok. 3800/3700 BC (Kukawka 2001, s. 77, 80, ryc. $2 ; 2010$ b, s. 110,189 , ryc. 10). $Z$ czasem ilość ceramiki o omawianych cechach technologiczno-stylistycznych na Kujawach wzrasta. Stanowi ona podstawowy wyznacznik źródłowy wyróżnionej przez A. Kośko grupy mątewskiej (Kukawka 2001, s. 80).

Materiały ceramiczne łączone w mątewski komponent kulturowy pod względem technologii wykonania, makro- i mikromorfologii są identyczne jak w grupie chełmińskiej.

\footnotetext{
${ }^{4}$ Prinke 2008, s. 436 - jednak schemat chronologii neolitu i sekwencji zmian kulturowych na Kujawach w tejże pracy (ryc. 2b) sugeruje o wiele późniejszą pozycję chronologiczną pasmowej ornamentyki grzebykowej, przypadającą na czas po zaniku kultury ceramiki wstęgowej rytej.
} 
Różnice dotyczą jedynie zdobienia. W mątewskim komponencie kulturowym występują niemal wyłącznie zdobienia pasmowo-grzebykowe. Pojawiają się one także w grupie chełmińskiej, lecz nie decydują o specyfice łączonych z nią materiałów. [...] Obie grupy (chełmińską i mątewską) w sferze adaptacji czytelnych w ceramice cech wywodzących się z kręgu KNa [kultury Narva - J. W.] różni jedynie stopień selekcji i transformacji zdobień obcych pod względem genetycznym (Kukawka 2001, s. 80-81).

Początkowo A. Kośko moment pojawienia się tzw. komponentu późnotrypolskiego, konstytuującego grupę mątewską, datował na fazy IIIB i przede wszystkim IIIC KPL na Kujawach (Kośko 1981, s. 127, ryc. 7, 18). Obecnie uważa się, że najstarsze ślady ceramiki zdobionej ornamentem pasmowo-grzebykowym pojawiają się wraz z materiałami KPL datowanymi na fazy IIB i IIIA (Kukawka 2010a, s. 25-26), co potwierdzają daty radiowęglowe $\mathrm{z}$ dwóch obiektów w Tarkowie Dolnym, pow. bydgoski, stan. 23, wynoszące $5200 \pm 55$ BP i 5100 \pm 40 BP (Daszkiewicz, Prinke 2001, s. 124) oraz Lembarga, pow. brodnicki, stan. 94: 5080 \pm 40 BP i 5050 \pm 35 BP (Kukawka 2010b, s. 165-166, tab. 2, nr 4-5). Na tej m.in. podstawie chronologia rozprzestrzeniania się ,cech mątewskich” została podzielona na trzy fazy: I (wczesną) - datowaną na terenie Kotliny Toruńsko-Bydgoskiej na lata 4050-3850? BC, II (klasyczną) - 3500-3150 BC i III (późną) 3150-3000 BC (Klochko, Kośko, Szmyt 2003, s. 408, fig. 1; Kośko 2003, s. 73; Kukawka 2010a, s. 21).

Ponieważ obecność cech subneolitycznych (ornament pasmowo-grzebykowy, domieszka tłuczonych muszli w masie garncarskiej) w kontekście ceramiki KPL na Niżu trwa ponad 1000 lat (najdłużej na ziemi chełmińskiej, do ok. 2800 BC) (Kukawka 2010a, s. 26), nie umożliwia to uściślenia momentu pojawienia się omawianej ceramiki w grupie łupawskiej, tym bardziej że nieznany jest dokładny kontekst archeologiczny, w jakim ona pojawiła się na osadzie w Poganicach. Można jedynie odwołać się do ogólnej sytuacji kulturowej w tym okresie na obszarze pomiędzy Kujawami, ziemią chełmińską i Pomorzem Środkowym.

W kontekście przedstawionych uwag wydaje się uprawomocniona opinia, że do zapoczątkowania wczesnoklasycznego etapu rozwoju grupy łupawskiej (początek fazy Ł III) doszło wskutek nasilających się kontaktów pomiędzy strefami nadmorską i wielkodolinną Niżu. Doprowadziły one ostatecznie do włączenia tej lokalnej jednostki w obręb wspólnoty szeroko rozumianej grupy wschodniej KPL. Główną rolę w tym procesie odegrała Wisła, a w zasadzie leżące na jej lewym brzegu obszary Kociewia, które były głównym rejonem przepływu informacji między tymi dwiema strefami (Wierzbicki 1999, s. 246-247), co wynikało przede wszystkim z jego usytuowania w obrębie największego na Pomorzu Gdańskim naturalnego południkowego szlaku komunikacyjnego (Felczak 2005b, s. 100-101, ryc. 2).

Obecność na tym obszarze wczesnoklasycznopucharowych grup ludności KPL potwierdzały już wcześniej nieliczne materiały ze stanowisk nad Wierzycą (Felczak 1984, s. 15). Wiele nowych odkryć, jakich dokonano w związku z badaniami na tra- 
sie autostrady A1, doprowadziło jednak do zmiany postrzegania tego peryferyjnego i jedynie okazyjnie penetrowanego - jak wcześniej sądzono - terenu. Najlepiej dowodzi tego skupisko stanowisk KPL nad dolną Wierzycą (Felczak 2005b, ryc. 30), wśród których najważniejsza jest osada w Barłożnie, pow. starogardzki, stan. 9, z dużymi domami słupowymi datowanymi na fazę IIIA KPL na Kujawach (Felczak 2005a, 2005b, s. 115-116, 118, ryc. 13-14). Jeszcze wcześniejsze są materiały z południowej części Kociewia, ze stan. 4 w miejscowości Stare Marzy, pow. Świecki (Kukawka 2012), dokumentujące pobyt ludności KPL, przybyłej tutaj najprawdopodobniej z terenu Kujaw. Ich chronologię określono na fazę IIB, a więc byłyby to najstarsze materiały KPL na lewym brzegu Wisły na północ od Kujaw (Kukawka 2012, s. 223-225). W świetle omawianej w niniejszej pracy problematyki szczególnie interesujące jest stan. $5 \mathrm{AB}$ z tej samej miejscowości. Odkryto tam osadę z fazy IIIBC KPL wraz z ceramiką ornamentowaną motywami pasmowo-grzebykowymi (Bokiniec, Chudziak, Cyrek, Gackowski 2004, s. 32, ryc. 6:1, 7:3, 8) i innymi zdobieniami subneolitycznymi (Bokiniec, Chudziak, Cyrek, Gackowski 2004, ryc. 6:4, 7:4?). Właśnie z tym odcinkiem rozwoju kujawskiej KPL wiązano już wcześniej kontynuację oddziaływań południowych na grupę łupawską, których wyznacznikiem miały być m.in., obok wątków zdobniczych II stopnia utworzonych za pomocą drabinki, także nieliczne ułamki ceramiki z pasmową ornamentyką grzebykową (Wierzbicki 1999, s. 248).

Słabiej czytelne i trudniejsze do datowania są pozostałości przenikania ludności łupawskiej na wschód i ewentualnie południowy wschód. Należą do nich przede wszystkim materiały ceramiczne rejestrowane w obrębie osad ludności kultury rzucewskiej położonych nad Zatoką Pucką (Osłonino, Rewa i Rzucewo pow. pucki) (Felczak 1983; Król 1991), ale ich pozycja chronologiczna w obrębie kultury rzucewskiej jest nieznana. Nie wiadomo nawet, czy mogą one wyznaczać na tym obszarze jakiś osobny epizod osadniczy, czy też poświadczają tylko istnienie kontaktów między tymi dwoma ugrupowaniami. Jak do tej pory za najdalej wysunięty na południowy wschód punkt osadniczy społeczności grupy łupawskiej uważane są Węsiory, pow. kartuski (Felczak 2005b, s. 113, ryc. 10), położone w środkowej części Pojezierza Kaszubskiego, w strategicznym punkcie na linii łączącej maksymalnie zbliżające się tutaj do siebie biegi rzek Wierzycy i Słupi, które dzieli w tym miejscu odległość zaledwie $19 \mathrm{~km}$.

Dyskusyjna pozostaje identyfikacja w obrębie ceramiki grupy łupawskiej czytelnych elementów subneolitycznych, tzw. leśnych, które mogłyby dostać się do rejonu Pomorza Środkowego bezpośrednio ze wschodu, bez pośrednictwa Kujaw czy ziemi chełmińskiej. Uznaje się, że kontakty ludności łupawskiej z tym kręgiem kulturowym nigdy nie nabrały większego znaczenia. Był to zapewne rezultat znaczącej roli doliny Wisły, tym razem jednak nie w charakterze szlaku łączącego północ z południem, a jako istotnej bariery ekologiczno-kulturowej między wschodem i zachodem. Szeroka i zabagniona delta Wisły była w tamtym czasie praktycznie 
niedostępna i prawie pozbawiona śladów pobytu człowieka. Jedynie na jej północnym skraju istniało osadnictwo kultury rzucewskiej związane z eksploatacją bursztynu (Haftka 1987, s. 32-33, mapa 1; Mazurowski 1987, s. 115-117). Społeczności tego ugrupowania potrafiły skutecznie uporać się z tym problemem komunikacyjnym, omijając obszar Żuław wzdhuż brzegu morskiego (Wierzbicki 1999, s. 248). Bardziej wymowne są w tej materii tylko źródła krzemienne, a konkretnie laurowate groty strzał (liściaki). Kilkadziesiąt takich grotów znaleziono na terenie osady poganickiej (Domańska 1975; Jankowska 1980, s. 144, 145, ryc. 21:14-16); powszechnie są one łączone genetycznie z ludnością północno-wschodnioeuropejską (MałeckaKukawka, Kukawka 1984, s. 25-26; Krzyszowski 1987, s. 153; Kukawka 1997, s. 159,2010 b, s. 126 , ryc. 11). Jest to jak do tej pory ,jedyna nieceramiczna kategoria źródeł o pochodzeniu subneolitycznym, którą udało się zidentyfikować w materiałach KPL" (Kukawka, 2001, s. 81).

Zarysowany powyżej szkic sytuacji kulturowej sugeruje, że choć nie można wykluczyć istnienia bezpośrednich kontaktów ludności grupy łupawskiej ze społecznościami subneolitu północno-wschodniego, to bardziej prawdopodobne jest, iż wiązane $\mathrm{z}$ tym kierunkiem oddziaływań elementy $\mathrm{w}$ postaci fragmentów naczyń zdobionych pasmowymi wątkami grzebykowymi, określanymi często mianem mątewskich, dotarły do rejonu dorzecza Łupawy poprzez ziemię chełmińską, a może i Kujawy, gdzie krążyły w obrębie wewnętrznej sieci wymiany informacji KPL (Kukawka 2010b, s. 193). Stamtąd szlak ich wędrówki prowadził poprzez Kociewie na północ, a następnie przecinał, wzdłuż Wierzycy i Słupi, Pojezierze Kaszubskie.

\section{BIBLIOGRAFIA}

Bokiniec E., Chudziak W., Cyrek K., Gackowski J.

2004 Sprawozdanie $\mathrm{z}$ ratowniczych prac wykopaliskowych przeprowadzonych $\mathrm{w}$ latach 2001-2002 w strefie planowanej budowy autostrady A-1 na odcinku województwa kujawsko-pomorskiego (b. woj. bydgoskie i toruńskie). W: Z. Bukowski (red.), Ogólnopolski program ochrony archeologicznych dóbr kultury zagrożonych planowana budowa autostrad. Raport 2001-2002. Wstępne wyniki konserwatorskich badan archeologicznych w strefie budowy autostrad w Polsce za lata 2001-2002 (Zeszyty Ośrodka Ochrony Dziedzictwa Archeologicznego. Seria B: Materiały Archeologiczne, s. 28-47). Warszawa: Ośrodek Ochrony Dziedzictwa Archeologicznego.

Czerniak L., Kośko A.

1993 Z badań nad genezq rozwoju i systematyka kultury pucharów lejkowatych na Kujawach. Poznań: Uniwersytet im. Adama Mickiewicza.

Daszkiewicz M., Prinke D.

2001 Problem relacji tzw. ceramiki pasmowo-grzebykowej i kultury pucharów lejkowatych na podstawie źródeł z Kujaw. W: J. Czebreszuk, M. Kryvalcevič, P. Makarowicz (red.), Od neolityzacji do początków epoki brązu. Przemiany kulturowe $w$ międzyrzeczu Odry i Dniepru między VI i II tys. przed Chr. (Archaeologia Bimaris - dyskusje 2, s. 121-129). Poznań: Wydawnictwo Poznańskie. 
Domańska L.

1975 Materiały krzemienne z osady kultury pucharów lejkowatych w Poganicach pow. Słupsk, stanowisko 4 (Uwagi wstępne). Koszalińskie Zeszyty Muzealne, 4(1974), s. 13-28.

Felczak O.

1983 Wyniki badań wykopaliskowych na osadzie kultury rzucewskiej w Rewie, gm. Kosakowo, woj. Gdańsk. Sprawozdania Archeologiczne, 35, s. 51-68.

Felczak O.

1984 Zagadnienie neolityzacji Pomorza Gdańskiego w aspekcie nowych odkryć archeologicznych między Wierzycą a Wisłą. W: A. Szymańska (red.), IX Sesja Pomorzoznawcza, Gdańsk 22-23.III.1984 r. Materialy (s. 10-19). Gdańsk: Polskie Towarzystwo Archeologiczne i Numizmatyczne.

Felczak O.

2005a Domostwa słupowe na osadzie ludności kultury pucharów lejkowatych w Barłożnie, gmina Skórcz, stanowisko 9. Problematyka badań nad wczesnym i środkowym neolitem na Pojezierzu Starogardzkim. Pomorania Antiqua, 20, s. 183-229.

Felczak O.

2005b Wczesny i środkowy neolit na Pomorzu Gdańskim w świetle odkryć na Kociewiu. W: M. Fudziński, H. Paner (red.), XIV Sesja Pomorzoznawcza, vol. 1, Od epoki kamienia do okresu rzymskiego (s. 99-122). Gdańsk: Muzeum Archeologiczne.

Haftka M.

1987 Mikroregion osadniczy Węgry-Gościszewo-Malbork w świetle kilkunastoletnich obserwacji. W: A. Pawłowski (red.), Badania archeologiczne $w$ woj. elblaskim w latach 1980-83 (s. 27-42). Malbork: Muzeum Zamkowe.

Jankowska D.

1977 Grupa tupawska kultury pucharów lejkowatych. [Maszynopis pracy doktorskiej, Biblioteka Instytutu Prahistorii UAM, Poznań].

Jankowska D.

1980 Kultura pucharów lejkowatych na Pomorzu Środkowym. Grupa tupawska. Poznań: Wydawnictwo Naukowe Uniwersytetu im. Adama Mickiewicza.

Jankowska D.

1990 Spoleczności strefy poludniowo-zachodniobaltyckiej $w$ dobie neolityzacji. Poznań: Wydawnictwo Naukowe Uniwersytetu im. Adama Mickiewicza.

Jankowska D.

2001 Elementy „leśne” w neolicie Pomorza. W: J. Czebreszuk, M. Kryvalcevič, P. Makarowicz, Od neolityzacji do początków epoki brązu. Przemiany kulturowe w międzyrzeczu Odry i Dniepru między VI i II tys. przed Chr. (Archaeologia Bimaris - dyskusje 2, s. 85-97). Poznań: Wydawnictwo Poznańskie.

Jankowska D., Wierzbicki J. (red.)

1993 Kopalnia surowców mineralnych kultury pucharów lejkowatych w Poganicach woj. Stupsk, stanowisko 4 (strefa 10). Poznań: Instytut Prahistorii Uniwersytetu im. Adama Mickiewicza.

Jastrzębski S.

1984 [recenzja] A. Kośko, Udział południowo-wschodnioeuropejskich wzorców kulturowych w rozwoju społeczeństw kultury pucharów lejkowatych. Grupa mątewska, Poznań 1981. Archeologia Polski, 29(1), s. 176-184.

Jażdżewski K.

1936 Kultura puharów lejkowatych w Polsce Zachodniej i Środkowej. Poznań: Polskie Towarzystwo Prehistoryczne. 
Klochko V.I., Kośko A., Szmyt M.

2003 A comparative chronology of the prehistory of the area between the Vistula and Dnieper: 4000-1000 BC. W: A. Kośko (red.), The Foundations of radiocarbon chronology of cultures between the Vistula and Dniestr: 4000-1000 BC (Baltic-Pontic Studies, 12, s. 396-414). Poznań: Instytut Wschodni i Instytut Prahistorii Uniwersytetu im. Adama Mickiewicza.

Kośko A.

1981 Udzial poludniowo-wschodnioeuropejskich wzorców kulturowych w rozwoju niżowych społeczeństw kultury pucharów lejkowatych. Grupa mątewska (Seria Archeologia, 14, Materiały do syntezy pradziejów Kujaw, 4). Poznań: Wydawnictwo Naukowe Uniwersytetu im. Adama Mickiewicza.

Kośko A.

1984 Łojewo, gm. Inowrocław, woj. Bydgoszcz, stan. 4, osada z fazy późnolubońskiej (V) kultury pucharów lejkowatych. Sprawozdania Archeologiczne, 35, s. 23-50.

Kośko A.

1988 Rozwój społeczeństw Kujaw w okresach późnego neolitu oraz w interstadium epok neolitu i brązu w aspekcie recepcji egzogennych wzorców kulturotwórczych. W: A. Cofta-Broniewska, Kontakty pradziejowych społeczeństw Kujaw z innymi ludami Europy (s. 145-183). Inowrocław: Urząd Miejski.

Kośko A.

2003 Radiocarbon chronology of the Mątwy Group of the Funnel Beaker Culture. The Question of chronological and cultural position of „linear-comb pottery”. W: A. Kośko (red.), The Foundations of radiocarbon chronology of cultures between the Vistula and Dniestr: 4000-1000 BC (Baltic-Pontic Studies, 12, s. 67-81). Poznań: Instytut Wschodni i Instytut Prahistorii Uniwersytetu im. Adama Mickiewicza.

Kośko A.

2010 W kręgu pewnej niedokończonej dyskusji. Fontes Archaeologici Posnanienses, 46, s. $11-18$.

Król D.

1991 Siedlungen der Rzucewo-Kultur in Osłonino, Fundstelle 2 und Rzucewo, Fundstelle 1, Gem. Puck. W: D. Jankowska (red.), Die Trichterbecherkultur. Neue Forschungen und Hypothesen. Material des Internationalen Symposiums Dymaczewo, 20-24 September 1988 (Teil II, s. 111-117). Poznań: Instytut Prahistorii Uniwersytetu im. Adama Mickiewicza, Zakład Archeologii Wielkopolski IHKM PAN.

Krzyszowski A.

1987 Z badań nad krzemieniarstwem społeczności kultury pucharów lejkowatych w dorzeczu dolnej i środkowej Parsęty. Folia Praehistorica Posnaniensia, 2, s. 127-197.

Kukawka S.

1989 Elementy północno-wschodnie w rozwoju kultury pucharów lejkowatych w świetle badań chełmińskiego mezoregionu osadniczego. Acta Universitatis Nicolai Copernici: Archeologia, 16, s. 3-27.

Kukawka S.

1991 Udział komponentu północno-wschodniego w wytwórczości ceramicznej kultury pucharów lejkowatych na ziemi chełmińskiej [Na marginesie pracy: A. Kośko, Osady kultury pucharów lejkowatych w Inowrocławiu-Mątwach, woj. Bydgoszcz, stan. 1, Inowrocław 1988]. Archeologia Polski, 35(1), s. 139-161.

Kukawka S.

1997 Na rubieży środkowoeuropejskiego świata wczesnorolniczego. Społeczności ziemi chetmińskiej w IV tysiacleciu p.n.e. Toruń: Wydawnictwo Uniwersytetu Mikołaja Kopernika. 
Kukawka S.

2001 Związki ugrupowań kultury pucharów lejkowatych z ludami kręgu kultury Narva. W:

J. Czebreszuk, M. Kryvalcevič, P. Makarowicz, Od neolityzacji do początków epoki brązu. Przemiany kulturowe w międzyrzeczu Odry i Dniepru między VI i II tys. przed Chr.

Kukawka S. (Archaeologia Bimaris - dyskusje 2, s. 75-83). Poznań: Wydawnictwo Poznańskie.

2010a Naczynia z pasmową ornamentyką grzebykową. Fontes Archaeologici Posnanienses, 46, s. $19-30$.

Kukawka S.

2010b Subneolit pótnocno-wschodnioeuropejski na Niżu Polskim. Toruń: Wydawnictwo Naukowe Uniwersytetu Mikołaja Kopernika.

Kukawka S.

2012 Ceramika naczyniowa kultury pucharów lejkowatych ze stanowiska 4 w Starych Marzach, gm. Drgacz, woj. kujawsko-pomorskie. Acta Universitatis Nicolai Copernici. Archeologia, 32, s. 201-228.

Małecka-Kukawka J., Kukawka S.

1984 Krzemienne groty strzał kultury pucharów lejkowatych na Pomorzu. Acta Universitatis Nicolai Copernici. Archeologia, 8, s. 3-34.

Mazurowski R.F.

1987 Badania żuławskiego regionu bursztyniarskiego ludności kultury rzucewskiej, Niedźwiedziówka, stanowisko 1-3. W: A. Pawłowski (red.), Badania archeologiczne w woj. elbląkim w latach 1980-83 (s. 79-128). Malbork: Muzeum Zamkowe.

Prinke D.

1988 Środkowoneolityczne zalążki procesów synkretyzacji kultury pucharów lejkowatych na Kujawach. W: A. Cofta-Broniewska (red.), Kontakty pradziejowych społeczeństw Kujaw z innymi ludami Europy (s. 93-105). Inowrocław: Urząd Miejski.

Prinke D.

2008 Społeczności neolitu na peryferiach kujawskiego mezoregionu kulturowego. W: J. Bednarczyk i in. (red.), Na pograniczu światów. Studia z pradziejów międzymorza bałtycko-pontyjskiego ofiarowane Profesorowi Aleksandrowi Kośko w 60. rocznice urodzin (s. 423-450). Poznań: Wydawnictwo Poznańskie.

Siuchniński K.

1969 Klasyfikacja czasowo-przestrzenna kultur neolitycznych na Pomorzu Zachodnim. Część

I. Katalog źródet archeologicznych. Szczecin: Muzeum Pomorza Zachodniego.

Siuchniński K.

1972 Klasyfikacja czasowo-przestrzenna kultur neolitycznych na Pomorzu Zachodnim. Część II. Opracowanie analityczne. Szczecin: Muzeum Pomorza Zachodniego.

Szurkowska K.

1982 Ceramika naczyniowa z osady ludności kultury pucharów lejkowatych w Poganicach, woj. stupskie (stanowisko 4, strefa 7). [Maszynopis pracy magisterskiej, Biblioteka Instytutu Prahistorii UAM. Poznań].

Świderski W., Wierzbicki J.

1990 Osada ludności kultury pucharów lejkowatych w Poganicach, woj. Stupsk, gm. Potegowo, stanowisko 4 (strefa 2). Poznań: Instytut Prahistorii Uniwersytetu im. Adama Mickiewicza w Poznaniu.

Weber A.

1983 Studia nad obrzadkiem pogrzebowym grupy tupawskiej kultury pucharów lejkowatych. Poznań: Wydawnictwo Naukowe Uniwersytetu im. Adama Mickiewicza. 
Werra D.

2012 Z badań nad tzw. mątewskim komponentem kulturowym w kulturze pucharów lejkowatych na ziemi chełmińskiej. Acta Universitatis Nicolai Copernici: Archeologia, 16, s. 229-252.

Wierzbicki J.

1997 Neolityczny grobowiec megalityczny z grobem korytarzowym w Lupawie, woj. słupskie, stan. 27. Materialy Zachodniopomorskie, 42(1996), s. 7-29.

Wierzbicki J.

1999 Eupawski mikroregion osadniczy ludności kultury pucharów lejkowatych. Poznań: Wydawnictwo Naukowe Uniwersytetu im. Adama Mickiewicza.

Wierzbicki J.

2013 Niezidentyfikowany przedmiot gliniany z osady kultury pucharów lejkowatych w Poganicach, pow. Słupsk, stan. 4. Folia Praehistorica Posnaniensia, 17(2012), s. 437-445.

\author{
POTTERY WITH A BAND AND COMB ORNAMENT FROM \\ THE FUNNEL BEAKER SETTLEMENT IN POGANICE, SŁUPSK COUNTY, SITE 4. \\ CONTRIBUTION TO THE STUDY OF DIRECTIONS OF INTERREGIONAL CONTACTS \\ OF THE ŁUPAWA GROUP COMMUNITIES
}

Sum mary

Interregional contacts of the communities representing the Łupawa group of the Funnel Beaker culture (hereinafter referred to as TRB from German Trichterbecherkultur) have been discussed from the very beginning of research on this culture, usually in context of its origins, while the focus regions were those of northern Germany and eastern Jutland. However, according to D. Jankowska, who assumed that elements genetically related to the Wielkopolska region and identified in the Lupawa group materials might have appeared in the area of the Łupawa River basin from the west, from upon the Parsęta River, equally important were contacts with the south. The first premise approving of such influences from the south, arriving into the Lupawa River basin probably along the lower Vistula River, was the discovery of a fragment of a vessel with a decorative motif of a four-wheeled cart at site 18 in Łupawa, Stupsk county. The next was the occurrence at site 27 in this location of a piece of pottery decorated with typical motif of the Wiórek-Jezuicka Struga stylistics (Toruń-Mokre).

Moreover, within TRB settlement in Poganice, site 4, there have been found two fragments of pottery decorated with band and comb motif (Fig. 1). This phenomenon has occurred, as it seems, only in the context of TRB materials. Its east-European origin is doubtless, but still, not fully explained issues of its genesis and chronology arise disputes. More than one theory attempts to explain the origin of this kind of ornamentation and relationship between it and TRB. A. Kośko has declared this type of decoration one of the basic indicators of so-called Mątwy group, which might have developed as a result of the adoption of Trypillian cultural patterns, whilst S. Kukawka considered it to be more likely that this type of material had resulted from the Subneolithic northeastern Narva culture. D. Prinke has gone even further, suggesting that vessels with band and comb ornament should be excluded from TRB materials and assumed a separate entity, older even than the Linear Pottery culture settlement. 
At the beginning, Kośko dated the first appearance of the so called "late-Tripillian component" that constitutes the Mątwy group, to phases IIIB and primarily IIIC of TRB in Kujawy. However, it is believed now that the oldest pottery decorated with band and comb ornament had appeared within TRB materials dating back to phases IIB and IIIA, which has been confirmed by radiocarbon dates from Tarkowo Dolne, Bydgoszcz county, estimated to 5200 BP and 5100 BP. Since the presence of subneolithic features in the context of TRB pottery within the Polish lowlands had lasted for more than 1000 years (the longest in Chelmno land, up to approx. 2800 BC) it does not permit for clarifying the emergence of discussed pottery in the Lupawa group. One could only refer to the general cultural situation during this period in the area between Kujawy, Chełmno land and Central Pomerania. It seems probable that the classical stage in development of the Łupawa group (phase $Ł$ III) was initiated by intensifying contacts between the coastal zones and great river valleys in the Polish lowlands. They led eventually to the inclusion of this local unit into the community of the eastern groups of TRB. The main role in this process was played by the areas located on the left bank of the Vistula River, a natural north-south oriented communication route. This has been confirmed by the presence of such sites as Stare Marzy, Świecie county, where a settlement dating from III BC phase of TRB has been discovered, along with pottery ornamented with band and comb motifs. It was this stage in development of TRB in Kujawy when southern influence on the Łupawa group intensified. On the other hand, the south-easternmost settlement of the Lupawa group is considered Węsiory, Kartuzy county, located between the Słupia and Wierzyca Rivers, receded from each other in the area of only $19 \mathrm{~km}$. Although direct contacts between the Lupawa group communities with those Subneolithic seem possible, much more probable appears that elements associated with that area got into the Lupawa River basin through Chełmno land, and perhaps also Kujawy. From there, their route led through Kociewie northwards, then crossed Pojezierze Kaszubskie along the Wierzyca and Słupia Rivers.

Translated by Lucyna Leśniak 